\title{
The efficacy of art therapy to reduce anxiety among bullying victims
}

Safaria, Triantoro

Universitas Ahmad Dahlan, Indonesia (safaria_diy@yahoo.com)

Yunita, Astrid

Universitas Ahmad Dahlan, Indonesia (astrid.yunita@gmail.com)

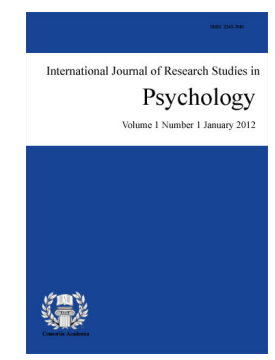

ISSN: $2243-7681$ Online ISSN: 2243-769X

OPEN ACCESS

\section{Abstract}

Based on previous study, many bullying victims showed a number of psychological problems. One of the negative effects experienced among bullying victims is anxiety. The objective of the present study was to reduce anxiety on bullying victims using art therapy. Anxiety questionnaire was used to measure the level of anxiety. The art therapy intervention was conducted in 5 sessions over 2 weeks. The subjects in this study were 10 students who have been experienced moderate levels of anxiety. The subjects were randomized into experimental groups and control group. Mann-Whitney was used to test the effect of art therapy in the experimental group and the control group. The result of analysis showed that the level of anxiety among experimental group was reduced, but not for control group $(p<0.05$ and $Z=-2.619)$. The conclusion of present study is art therapy decrease the level of anxiety in the experimental group. The implications of study are discussed.

Keywords: anxiety; art therapy; bullying victims 


\section{The efficacy of art therapy to reduce anxiety among bullying victims}

\section{Introduction}

Currently a case of violence or aggression is growing considerably among students in Indonesia (Detiknews, 2014). The type of violence can be occurred either by the teacher to the students, or the student to the student. The violence is not only happened physically but also psychologically. One type of violence in school that happens repeatedly is known as bullying (Olweus, 2001). Bullying is aggressive behavior that is intended to hurt or make other people feel distress, occurs repeatedly, and took place in an imbalance of power between the bully and the victim (Krahe, 2001; Olweus, 2001).

Bullying causes many negative effects, not only for the victim, it may also have long-term effects on the perpetrators. Bullying can lead to high stress and also a risk factor associated with antisocial behavior and criminal behavior (Morrison, 2002; Wong, 2004). Bullying can also create an insecurity feeling, makes the victim helplessness, harm effect on the health and well-being, and reduce student's academic performance (Morrison, 2002; De Wet, 2005; Alikasifoglu, et al, 2007). Some of negative consequences caused by chronic bullying including anxiety, depression, social withdrawal, low self-esteem, avoidance of school, increased suicidal tendencies, learning and sleeping difficulties (Perry, Hodges, \& Egan, 2001; Rigby, 2001; Sarazen, 2002; Wong, 2004; Reiter dan Lefler, 2007; Fleming dan Jacobsen, 2009).

Lange and Pulley (2002) suggested that victims of bullying suffer psychological, emotional, developmental, and academically. The victims feel that they "deserve" to be bullied. The victims of bullying have a difficulty in making friends with other children at school, because his friends fear that they will be bullied because befriends with the bullying victim. Frequently, the victim absent to the school, because they assume if they do not attend to school, then the frequency of bullying will be reduced.

Previous studies show that bullying is a worldwide problem. Several study from America, Canada, UK, and Japan, found that $20 \%$ to $30 \%$ of student involved in bullying (Craig, Pepler, \& Atlas, 2000; Rios-Ellis, Bellamy, \& Shoji, 2000; Berthold \& Hoover, 2000; Dake \& Price, 2003). $7 \%$ to $23 \%$ was conducted bullying, while 5\% to $12 \%$ were identified as victim (Forero, McLellan, Rissel, \& Bauman, 1999; Juvonen, Graham, \& Schuster, 2003). Wolke, Woods, Bloomfield, and Karstadt (2001) suggested that approximately 8 to $46 \%$ of children have the experience of bullying since attending elementary school.

Kvarme et al. (2010) in his study found that positive interaction between peers is very important for developing child's self-confidence. His study suggested that child feel bad if treated negatively because of their appearance. Negative words are very important in shaping child's self-image. If a victim is constantly told that he looks ugly, then he/she will believe it. Bullying words will lead the victims experience anxiety and even become depressed. Previous studies indicate that victims of bullying are more likely to experience anxiety compared with non-victim. They are also more likely to experience higher levels of social anxiety than non-victim (Swearer \& Berry, 2012).

\section{Literature review}

\subsection{Anxiety among Bullying victim}

Froggatt (2003) suggested that the term anxiety refers to feelings of discomfort and fear, coupled with some unpleasant physical symptoms, including tension (muscle), accelerated heart rate, breath ragged, dry mouth, sweating and trembling body. If the anxiety is getting worse, negative effects can arise, for example dizziness, fainting, chest pain, blurred vision, feeling of choking, nausea and frequent bowel movements or diarrhea. 
Anxiety can sometimes be regarded as a symptom similar to fear, so as to interfere with the realization of healthy behaviors. Darajat (1998) suggested that anxiety is a manifestation of a variety of mixed emotions that occur when a person is experiencing distress. This situation requires a proper and satisfactory completion so that people will feel safe, but in reality not all problems can be resolved by a person and some have tended to be avoided.

Dudley and Rollings (2010) suggested that anxiety in childhood and adolescence occurs with a percentage of around 15-20\%, and more common in women. Anxiety has also a relationship with the occurrence of depression, tends to increase with age, and long-term repercussions (Fleming and Jacobsen, 2009). Anxiety caused by bullying behavior, usually appearing in the form of avoidance of threatening situations in school, better known as school refusal. One cause of school refusal is bullying incident (32\%) (Dudley \& Rollings, 2010).

Sansone and Sansone (2008) in their study found several negative consequences among bullying victims including a variety of psychological problems such as somatic symptoms, difficulties in socialization, anxiety, depression, increasing of suicidal ideation, eating disorders (bulimia and anorexia nervousa). Somatic symptoms including reduced appetite, headache, neck pain, shoulder pain, back pain, difficulty sleeping, stomach pain, and fatigue. Anderson (2007) found that bullying victims have a negative interpretation of the world and the neighborhood as a unsafe place. Besides Anderson (2007) also found the psychological impact of bullying for the victim such as emotional stress, impairment the capacity to learn, development social anxiety, school phobia, decreasing self-confidence, feeling ostracized, become withdrawn and depressed.

\subsection{Art therapy for anxiety disorder}

Shri (2010) suggested that CBT (cognitive behavioral therapy), behavior therapy, and psychodynamic therapy can be used to treatment anxiety disorders. Psychodynamic therapy focused on how to express traumatic experiences in expressive and spontaneous way. This opportunity gives a person to explore his/her traumatic feelings, unconscious conflicts, which comes from the past. One of the basic psychodynamic therapies that can be used is art therapy.

Art therapy provides an opportunity to express and actualize for a person who has limitations in revealing the source of anxiety or traumatic experiences through the medium of drawing. Spontaneous expression through art or free association by using art (drawing or writing) is directly solved and integrates unfinished traumatic experiences. In psychodynamic theory, the unconscious state stored hidden and distorted experiences. Once these unidentified experiences can be expressed through art, then the unsolved hidden experiences will resolve and integrate to new insight (Malchiodi, 2005).

Art therapy can literally be interpreted as combining the two disciplines, the art and the science of psychology. According to the American Art Therapy Association, art therapy is based on the belief that the creative process in the arts can help and facilitate the healing process and provide new meaning for a person. Art therapy is more commonly found in the form of drawings, paintings, sculpture, and photography. Various forms of visual art can facilitate a translation process of hidden and ambiguous symbol by a creative process of art (Malchiodi, 2005). Art therapy is a creative process to help patients express their thoughts and feelings non-verbally. Art therapy can be described as "symbolic speech ". In a sense, through art therapy, material that cannot be said through words because a complicated and complex trauma can be channeled through drawing or painting. This approach, which is often called the "art psychotherapy " (Malchiodi, 2005).

Malchiodi (2003) suggests that trauma is a sensory experience, through drawing activity the cognitive process utilize sensory memories of trauma to be resolved. Drawing provides a "safe vehicle " that is safe for children/teens to communicate something that cannot describe it in words. Drawing involves children in active engagement for self-healing. Drawing provides a visual focus to encourage children focus for their specific trauma. Drawing activity also provides a space for children/teens to tell their story and experiences. Drawing 
also provides a space to reduce reactivity (anxiety memories) through visual reexposure (imagine returning anxious situations), which is repeated in the drawing media. Malchiodi (2003) suggested that art therapy encourage an action-oriented work with a way to explore and communicate their thoughts and feelings. Art therapy can maximize the use of imagination, assist individuals in finding and developing the right solution, which can lead to self-improvement actions and changes to a more positive direction.

Children are basically very creative and can easily describe the feelings and emotions through creative art. Children have a lot of difficulty in putting emotions and feelings such as anger, hatred, and hidden issue of sexual harassment, domestic violence, chaos in life experienced, and many other problems in words (Rubin, 2005). The artwork is used as a safe form of symbolic realism that can not hurt traumatic and vulnerable child. If the child looks too tense before the treatment begins, the child can be given relaxation to create a relaxation state. After the child feel relax, he/she can given a more spontaneous expression and imagination freely (Rubin, 2005).

Art therapy can also be applied to adolescents. At this age, they cannot easily disclose their problem and it sometimes makes therapist difficult to explore the problems that they are facing. Through art therapy and individual art work, they can express their creativity to channeled all the emotions and thoughts that overburden them. Art therapy can clear the path to the root of the problem, because of unreadable symbols can form and exist in the art work, either consciously or unconsciously (Nainis, 2005). Finally, unreadable and traumatic symbol can integrate in a new meaning that relates directly to the root of the problems being faced (Rubin, 2005). Art therapy can be used as a communication tool and more than just a verbal talk. Children are also more easily express the events that left the trauma through artistic creations rather than using words. Through art, traumatic events that have been stored in the subconscious also be lifted to the surface. If traumatic emotions are connected, then the recovery process will be more faster.

In the first session, children are allowed to make any use of the tools that have been provided by the therapist. During the session children should be comfortable. If the child does not want to be disturbed then the therapist should not encourage children to talk. but only if the child invites the therapist to talk, it can be done. During the session, the therapist asks the child to tell what they make and what emotions he/she felt. In some children, will spontaneously tell what made but there are children who do not want to talk on the session so that after the session ends, the therapist interviewed the child (Rubin , 2005).

Almost adolescents have difficulty to share their traumatic problems to other, especially to adults. Art therapy may be able to facilitate the youth to share their problem in more secure form. Art therapy does not require teen to tell the problems verbally, but put it in the form of images, drawing and color. Art therapy process make teen easier to disclosed and explore their traumatic problem. Based on this, the art therapy is considered as an appropriate medium for granted, especially in adolescents who experience problems such as anxiety (Rubin, 2005; Malchiodi, 2005).

Chambless (2010) suggested that the best predictor of stress reaction is individual's perception of the stressor. When a person sees himself does not have the necessary resources to deal with stressors, then the psychological symptoms associated with stress (e.g., anxiety, depression, social withdrawal, and so on) are likely to increase. Coping resources have been found to be a significant moderator of psychological distress, including depression, anxiety, and general psychological distress (Safaria, Othman, \& Nubli, 2010). Bullying on the one hand can be considered as a stressor when the victim experiences it. Bullying will be perceived by the victim as a constant threat to personal resources, including physical safety, emotional well-being, and self-esteem; with interpersonal relationships (Chambless, 2010).

Hoisko, Uusiautti, and Määtä (2012) found the role of imagination as a creative coping that can boost positive inner strength, and human intuition. In their study, artistic creative methods were used to overcome the problems of bullying victims. Hoisko, Uusiautti, and Määttä (2012) suggest that interest in the arts helps to channel victim's anxiety in the artwork and thus the unresolved trauma can be solved and released in an artwork. Chambala (2008) suggested that art therapy is suitable for individuals who suffer from anxiety disorders because 
individuals can express themselves by creating shapes, colors, and designs. Chambala (2012) also stated that art works are more beneficial than simply relying on the words to express unresolved trauma and anxiety. A picture can often be more appropriate to describe and express the unresolved trauma than in words. The power of art therapy with drawing techniques for clients diagnosed with anxiety lies in the idea that the creative process allows the client to engage in self-expression and personal exploration (Malchiodi, 2005). Art process allows person to step back, look inside, and identify strengths and weaknesses by creating a real depiction of his mental state (Malchiodi, 2005).

Learmonth and Huckvale (2001) suggested that the process of art therapy helps individuals to share unpleasant experience, express and restrain his feelings, increase self-esteem, and find new solutions to their problems. The art process helps person to improve the individual's ability to tell about his views, and be able to identify and manage their feelings. The process of art therapy is able to be a safe place for individuals to practice a taking risks action and making mistakes, learn new skills, develop a sense of tolerance to the anxiety experienced, involved in the process of imagination, and look at the problem from a different perspective. In addition, art therapy helps individuals in developing emotion regulation (Learmonth \& Huckvale, 2001; Malchiodi, 2005).

Malchiodi (2005) suggested that the traumatic experiences can be done through the process of expressive therapy, particularly art therapy. Through art therapy, individuals who have limitations in revealing the source of traumatic experience, get out and express it through picture or images. Through picture or images person can represent and channel their thoughts, feelings and anxiety that cannot be expressed verbally. Spontaneous expression through art or free association on a medium of art (drawing or writing) can explore directly into the unconsciousness. Because in the unconscious state is stored a hidden and distorted traumatic experiences, and once these experiences can be expressed and identified through, it will open the opportunity to change it (Malchiodi, 2005).

Art therapy is not only helps among adult, but also can help children and adolescents who lack on words to express their problem. Children and teenagers are basically very creative and artistic, could easily describe the feelings and emotions through creative art. Art therapy can become a medium of safe work to form a symbolic realism of traumatic experiences (Rubin, 2005). The purpose of this study was to determine whether art therapy can reduce and minimize bullying victim's anxiety. Reducing of anxiety among bullying victims will be showed on cognitive, affective, physiologic and behavior dimensions.

\subsection{Hypothesis}

The hypothesis of the present study is "art therapy can reduce anxiety among bullying victims. The reducing of anxiety score is showed on cognitive, affective, physiologic, and behavior dimension of bullying victims".

\section{Method}

\subsection{Subject}

The subjects of present study were teenagers who have experience bullying at school and has medium anxiety score measured by anxiety scale. The participant ages between 12 to 15 years old, gender is boy and girl. The subject has also never got psychological intervention regarding their problem. All subjects have also agreed to be involved in the study. They fill in a inform consent without a coercion, and can at any time decide not to be involved in the study.

\subsection{Questionnaire}

Anxiety scale was used to measure the anxiety level of subject. The anxiety scale of bullying victims was 
adapted from Haber and Runyon (1984). The summated rating scale method was used. The scale has five alternative answers from (0) never, (1) sometimes, (2) fairly often, (3) frequent, (4) to occur at any time. The five choices answer indicates whether or not the subject frequently experience anxiety regarding bullying. Examples of the items are as follows: "I worry when I go to school" "I easily worry about everything in school" "I worry if I will be bullied by other kids" "I easily get tension". The Cronbach's alpha was used to test the reliability of anxiety scale. The reliability coefficient of the scale is 0.858 .

\subsection{Experimental design}

Randomized pre-posttest control group design was conducted. In these study experimental subjects was given a pre-test prior to the treatment by administering the anxiety scale. Experimental subjects were given art therapy in the form of drawing activities. In final session experimental subject was given a post-test using the same scale to see whether there is a change in anxiety score. Subjects in the control group was also given the same pre-test, without the provision of treatment with a time delay equal to the experimental group, and then given a post-test. After administering the post-test, the control group was also given treatment in the form of art therapy.

\subsection{Art therapy module}

In the present study, a modification and combination of several art therapy themes, from Leibmann (2004), Malchiodi (2005), and Lowenstein (2011) was applied. The selection of themes in art therapy activities are tailored to the stage and the path flow of anxiety, which starts from the recall situations that cause anxiety to the release process. The first meeting consisted of four activity, session one focuses on building rapport which aims to familiarize the group members, therapists as well as observers and facilitators. Session two was an ice breaking games that aims to help the subjects to adjust to other people. Session three focuses on activities that facilitate subject to recognize their anxiety. Session four is the free drawing theme activity that aims to provide an opportunity for the subjects to familiarize themselves with the drawing.

The second meeting focuses on activities that explore subject anxiety by drawing the "some things you fear" theme. This activity aims to explore the source of fear and subject's anxiety, knowing the cause of it, face it, challenge it and find methods to overcome it. The third meeting facilitates activities that address the problem by drawing the "crossing the river" theme. This activity aims to explore how subjects in solving their problems and help them to overcome the problem by finding a way out. The fourth meeting focuses on activities that release anxiety and traumatic experiences by drawing on the theme "draw a safe place ". This activity aims to encourage the subject to use a secure place as a way to build strength when face a problem. The fifth meeting focuses on activities that evaluate overall therapy process, giving the post-test, and a conclusion speech by therapist.

\subsection{Data analysis}

The data was analyzed by using Mann-Whitney test to determine the effect of art therapy to decrease anxiety scores in the experimental group and the control group. In addition, Wilcoxon test was also performed to examine whether there is any difference between pretest and posttest in the experimental group and the control group separately (Sugiyono, 2008).

\subsection{Informed consent}

Informed consent was completed by participants on May 6, 2013. Consent form contains an introduction, a brief overview of the process of the therapy, the rights and obligations of the participants, the benefits and risks of participation, confidentiality, and the contact of researcher. Researchers also responsible to provide referrals to professional psychologists in the implementation of the intervention if the subject is found have increasing anxiety and distress or any side effect that cannot be anticipated. 


\section{Discussion}

Mann Whitney test found differences in anxiety scores between experimental group and control group. This result suggests that art therapy decrease anxiety level among bullying victims in the experimental group, not for control group. Table 1 depicts the result of Mann Whitney test between experimental and control groups.

Table 1

Mann Whitney test between Experimental and Control Groups

\begin{tabular}{ll}
\hline Statistic & Score \\
\hline Mann-Whitney U & .000 \\
Wilcoxon W & 15.000 \\
Z & -2.619 \\
Asymp. Sig. (2-tailed) & .009 \\
Exact Sig. [2*(1-tailed Sig.)] & .008 \\
\hline
\end{tabular}

The second step of analysis is to perform Wilcoxon test to examine pretest and posttest in the experimental group and control groups separately. In the experimental group there is a significant difference on pretest and posttest of anxiety score $(p=0.043<0.05)$, whereas in the control group there is no significant difference on pretest and posttest of anxiety score $(p=0.063>0.05)$. This means that art therapy interventions can decrease anxiety score in the experimental group. Conversely the anxiety score did not change on the control group. Table 2 describes Wilcoxon test for experimental group, and table 3 shows Wilcoxon test for control group.

\section{Table 2}

Wilcoxon test for experimental group

\begin{tabular}{ll}
\hline Statistic & Score \\
\hline $\mathrm{Z}$ & -2.023 \\
Asymp. Sig. (2-tailed) & .043 \\
\hline
\end{tabular}

Table 3

Wilcoxon test for control group

\begin{tabular}{ll}
\hline Statistic & Score \\
\hline$Z$ & -1.841 \\
Asymp. Sig. (2-tailed) & .066 \\
\hline
\end{tabular}

The change of anxiety score can be seen in figure 1 for the experimental group, and figure 2 for the control group.

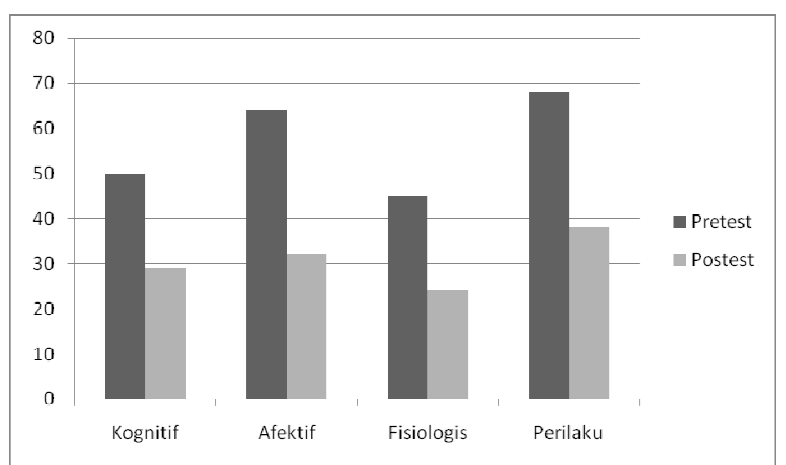

Figure 1. The change on anxiety scores between pretest and post-test in the experimental group 


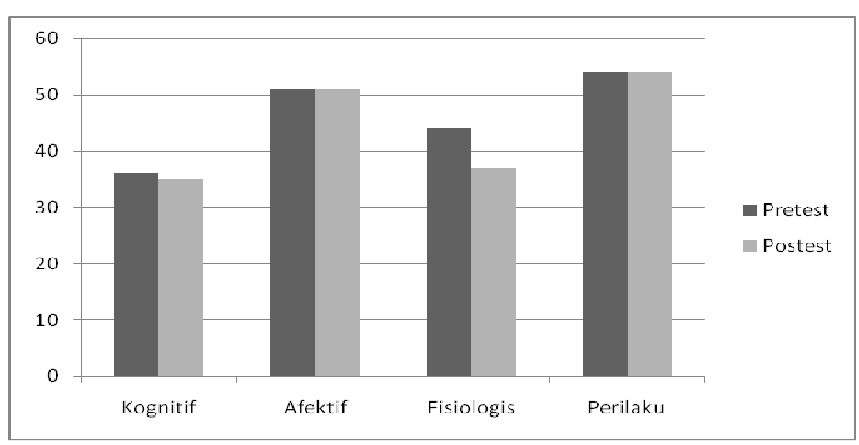

Figure 2. The change on anxiety scores between pretest and post-test in the control group

Based on the figure 1 above, it can be seen that the decreasing of post-test scores on the experimental group was most intense in the affective aspect as much as $50 \%$, followed by physiological aspect as much as $46 \%$, behavioral dimension which fell by $44 \%$, and dimension cognitive as much as $42 \%$. Meanwhile, in the control group did not decrease significantly in every aspect. In the control group only in the physiological dimension $(16 \%)$ and the cognitive dimension (3\%) decrease, but this changes is not significant. Table 4 to table 7 describes the result of Mann Whitney test on every aspect between the experimental group and the control group.

\section{Table 4}

Mann-Whitney test for cognitive dimension

\begin{tabular}{ll}
\hline Statistic & Score \\
\hline Mann-Whitney U & .000 \\
Wilcoxon W & 15.000 \\
Z & -2.685 \\
Asymp. Sig. (2-tailed) & .007 \\
Exact Sig. [2*(1-tailed Sig.)] & $.008^{\mathrm{a}}$ \\
\hline
\end{tabular}

\section{Table 5}

Mann-Whitney test for affective dimension

\begin{tabular}{ll}
\hline Statistic & Score \\
\hline Mann-Whitney U & .000 \\
Wilcoxon W & 15.000 \\
Z & -2.652 \\
Asymp. Sig. (2-tailed) & .008 \\
Exact Sig. [2*(1-tailed Sig.)] & $.008^{\mathrm{a}}$ \\
\hline
\end{tabular}

\section{Table 6}

Mann-Whitney for physiological dimension

\begin{tabular}{ll}
\hline Statistic & Score \\
\hline Mann-Whitney U & .000 \\
Wilcoxon W & 15.000 \\
Z & -2.635 \\
Asymp. Sig. (2-tailed) & .008 \\
Exact Sig. [2*(1-tailed Sig.)] & $.008^{\mathrm{a}}$ \\
\hline
\end{tabular}


Table 7

Mann-Whitney test for behavioral dimension

\begin{tabular}{ll}
\hline Statistic & Score \\
\hline Mann-Whitney U & 1.000 \\
Wilcoxon W & 16.000 \\
Z & -2.432 \\
Asymp. Sig. (2-tailed) & .015 \\
Exact Sig. [2*(1-tailed Sig.)] & $.016^{\mathrm{a}}$ \\
\hline
\end{tabular}

Based on the results of the Mann Whitney test above it was found that there is a significant difference on cognitive dimension of anxiety $(p=0.007<0.05)$, affective dimension of anxiety $(p=0.008<0.05)$, physiological dimension of anxiety $(p=0.008<0.05)$, and behavioral dimension of anxiety $(p=0.016<0.05)$.

In this study, art therapy intervention can reduce anxiety score among experimental group. While the control group showed no different anxiety score in pretest and post-test measurement. Several factors that influence the reduction of anxiety scores among experimental group namely: be active during the therapy process, enthusiasm in accepting the assigned material, a sense of togetherness among the subjects in the group, the courage to disclose and share traumatic and unpleasant experiences through drawing, and the process of insight through art therapy that can resolve subject's negative emotions (anxiety, fear, sadness, disappointment, anger). Art therapy can reduce all dimension of anxiety (cognitive, affective, physiological, and behavioral). Affective dimension was the dimension that the most decreasing as much as $50 \%$ because of art therapy intervention among bullying victims.

Chambala (2008) found in his study that the primacy of art therapy for individuals diagnosed with anxiety lies in the idea that the creative process provides a way for individuals to unite between expression and self-exploration. The creative process in art therapy makes subject be able to rewind back and see more clearly into the problems, then they can identify the strengths and weaknesses of each to pour into the picture. Chambala (2008) suggests that art therapy is appropriate for individuals with anxiety. Expressing process in art therapy help bullying victims to cathartic the traumatic event through making an image, colored it, and designs it.

Visnola et al. (2010) found in their study that art therapy has an effect on the stress and anxiety of employees. They found that the average level of stress and anxiety of employees is significantly reduced compared with the control group. Their findings have an implication that art therapy may be able to apply as a preventive intervention for stressful employees. Through art therapy intervention they can get an understanding about stressful situations, be able to manage the anxiety experience, reacting adequately to stressful situation, cope positively with stress, thus can improve their quality of life in creative ways. Study by Zastrow (2009) found that art therapy group may have positive contribution to subject, because the similarities of experiences between the group members can lead to emotional bonding and closeness. Group members with similar problems tend to have similar characteristics that will provide greater opportunities to share, openness in telling the problem, and can better understand what is perceived other group members.

Self-actualization and disclosure that inherent in the process of making art seems to help people with anxiety disorders (Chambala, 2008). In contrast to the apparent behavior, anxiety cannot be seen, only felt like any other emotion. Some clients also stated that each color represents a different emotion of anxiety experienced, and represent all the thoughts that come to mind (Chambala, 2008). Some of the subjects in the present study stated that the results of an image with a combination of light and bright colors makes they calm and satisfy when looking back to the picture and then tell the story about it.

\section{Conclusion}

Art therapy intervention can reduce bullying victims' anxiety. Several factors that contibute in reducing the 
anxiety scores of bullying victims namely: be active during the therapy process, be enthusiasm in accepting the assigned material, a sense of togetherness among the subjects in the group, the openness to share unpleasant experiences through images, and get an insight during art therapy process. In addition, it was found that all anxiety dimensions decreased significantly after administration of the art therapy intervention.

Art therapy can help the subject to resolve unpleasant experiences in a more safe and fun activity, create a relaxation mind, became calmer, get an opportunity to share traumatic feeling in groups, lighten the burden of thinking, get positive feedback and support from other victims, and get an understanding that a problem can be poured through the drawing activity.

The implication of the study for the school authority is to organize art therapy activities for bullying victims. Through art therapy activity the bullying victims will get an opportunity to disclose and resolve their traumatic experiences. Besides, the school authority should implement an prevention action to reduce bullying incidence in the school. For the bullying victim, they encourage to apply and implement art therapy activity when feel overwhelm with anxiety. Use art therapy as positive coping and as a self-help intervention to reduce the burden caused by bullying.

For the further study is recommended to develop and provide additional themes in art therapy intervention with drawing techniques for other traumatic problem. For example by adding a theme depicting barriers or obstacles in the face of a problem, to explore the perceived barriers and how the subject feels it and describe it in appropriate ways. One of the present study limitations is not apply a follow- up test to see how effective and longer art therapy interventions can reduce the symptoms of anxiety. Follow-up test is useful to certain the long-term effect of art therapy after intervention done.

\section{References:}

Alikasifoglu, M., Erginoz, E., Ercan, O., Uysal, O., \& Kaymak, D.A. (2007). Bullying behaviours and psychosocial health: Results from a cross-sectional survey among high school students in Istanbul, Turkey. European Journal Pediatric, 166, 1253-1260. http://dx.doi.org/10.1007/s00431-006-0411-x

Anderson, G. (2007). The impact of bullying in school on the adolescent's sense of self. Unpublished Thesis. Faculty of Humanities University of Pretoria. South Africa.

Berthold, K.A., \& Hoover, J.H. (2000). Correlates of bullying and victimization among intermediate students in the Midwestern USA. School Psychology International, 21(1), 65-78. http://dx.doi.org/10.1177/0143034300211005

Buchalter, S. I. (2004). A practical art therapy. USA: Jessica Kingsley Publishers.

Calhoun, J. F., \& Acocella, J. R. (1990). Psychology of adjusment and human relationship. New York: Mc Graw Hill Book Company.

Chambless, C. B. (2010). Long-term effects of bullying: Exploring the relationships among recalled experiences with bullying, current coping resources, and reported symptoms of distress. Unpublished Thesis. Department of Counseling and Psychological Georgia State University.

Chambala, A. (2008). Anxiety and art therapy: Treatment in the public eye. Journal of the American Art therapy Association, 25(4), 187-189. http://dx.doi.org/10.1080/07421656.2008.10129540

Darajat, Z. (1998). Kesehatan mental jiwa. Jakarta: CV. Haji Masagung.

Detiknews (2014). Survy RI-UNICEF. Retrieved http://news.detik.com/read/2014/05/16/204026/2584418/10/survei-ri-unicef-15-juta-remaja-alami-keker asan-seksual-1-tahun-terakhir

Dudley, A., \& Rollings, S. (2010). Anxiety and school refusal. The Journal of Early Adolescence, 30(5), 691-706.

Fleming, L. C., \& Jacobsen, K. H. (2009). Bullying and symptoms of depression in middle school students. Journal of School Health, 79(3), 130-137. http://dx.doi.org/10.1111/j.1746-1561.2008.0397.x

Froggatt, W. (2003). Free from stress: Guide to manage anxiety. Jakarta: PT. Bhuana Ilmu Populer. 
The efficacy of art therapy to reduce anxiety among bullying victims

Haber, A., \& Runyon, R. P. (1984). Psychology of adjustment. Illinois: The Dorsey Press.

Hoisko, S., Uusiautti, S., \& Määttä, K. (2012). How to overcome bullying at school? The adult survivors' perspective. International Journal of Academic Research in Business and Social Sciences, 2(11), 58-72.

Kim, Y. S., \& Leventhal, B. (2008). Bullying and suicide: A review. International Journal Adolescence Medical Health, 20(2), 133-154. http://dx.doi.org/10.1515/IJAMH.2008.20.2.133

Kinrys, G., \& Wygant, L. E. (2005). Anxiety disorder in woman: Does gender matter to treatment. Rev Bras Psiquiatr, 27(2), 43-50. http://dx.doi.org/10.1590/S1516-44462005000600003

Krahe, B. (2001). Perilaku agresif (Aggresive behavior). Translator: Soetjipto, H. P., \& Soetjipto, S. M. Yogyakarta: Pustaka Pelajar Offset.

Kvarme, L. G., Helseth, S., Saeteren, B., \& Natvig, G. K. (2010). School children's experience of being bullied and how they envisage their dream day. Scandinavian Journal of Caring Sciences, 24, 791-798. http://dx.doi.org/10.1111/j.1471-6712.2010.00777.x

Lange, M. D. M., \& Pulley, S. C. (2002). Bullying: The phycisian's role. Wisconsin Medical Journal, 101(6), 26-29.

Learmonth, M., \& Huckvale, K. (2001). Why art psychotherapy makes sense. England St. Thomas, Exeter: Insider Art.

Liebmann, M. (2004). Art therapy for groups: A handbook of themes and exercises: second edition. New York: Brunner-Routledge Taylor \& Francis Group.

Lowenstein, L. (2011). Favorite therapeutic activities for children, adolescents, and families: Practitioners share their most effective interventions. Canada: Champion Press.

Luukkonen, A. U. (2010). Bullying behaviour in relation to psychiatric disorders, suicidality and criminal offences: A study of under-age adolescent inpatients in northern finland. Finland Oulu: University of Oulu.

Malchiodi, C. A. (2003). Handbook of art therapy. USA: The Guilford Press.

Malchiodi, C. A. (2005). Expressive therapies. New York: The Guilford Press.

Morrison, B. (2002). Bullying and victimisation in schools: A restorative justice approach. Australia: Australian Institute of Criminology.

Nainis, N., Paice, J. A., Ratner, J., Wirth, J. H., Lai, J., \& Shott, S. (2006). Relieving symptoms in cancer: Innovative use of art therapy. Journal of Pain and Symptom Management, 31(2), 162-169. http://dx.doi.org/10.1016/j.jpainsymman.2005.07.006

Reiter, S., \& Lefler, N. L. (2007). Bullying among special education students with intellectual disabilities: Differences in social adjustment and social skills. Intellectual and Developmental Disabilities, 45(3), 174-181. http://dx.doi.org/10.1352/1934-9556(2007)45[174:BASESW]2.0.CO;2

Rigby, K. (2003). Consequences of bullying in schools. The Canadian Journal of Psychiatry, 48(9), 583-590.

Robinson, K. (2010). Bullies and victims: A primer for parents. Minneapolis Public Schools: National Association of School Psychologist.

Rubin, J. A. (2005). Child art therapy. New Jersey: John Wiley \& Sons, Inc.

Safaria, T., Othman, A., \& Nubli, M. (2010). Religious coping, job insecurity and job stress among Javanese academic staff: A moderated regression analysis. International Journal of Psychological Studies, 2(2), 159-169. http://dx.doi.org/10.5539/ijps.v2n2p159

Sansone, R. A., \& Sansone, L. A. (2008). Bully victims: Psychological and somatic aftermaths. Psychiatry (Edgmont), 5(6), 62-64.

Sarazen, J. A. (2002). Bullies and their victims: Identification and interventions. Unpublished Thesis. Menomonie: Master of Science Degree With a Major in Guidance and Counseling, The Graduate College University of Wisconsin-Stout.

Shri, R. (2010). Anxiety: Causes and management. International Journal of Behavioral Science, 5(1), 100-118. Sugiyono. (2008). Statistika non-parametris untuk penelitian (Non-parametric statistic for research). Bandung: Alfabeta.

Swearer, S., \& Berry, B. (2012). Bullying and anxiety: What's the connection?. Diakses dari http://www.education.com/reference/article/bullying-anxiety-what-connection/. 
Safaria, T. \& Yunita, A.

Wolke, D., Woods, S., Bloomfield, L., \& Karstadt, L. (2001). Bullying involvement in primary school and common health problems. Arch Dis Child, 85, 197-201. http://dx.doi.org/10.1136/adc.85.3.197

Visnola, D., Sprudsa, D., Baíe, M. A., \& Piíe, A. (2010). Effects of art therapy on stress and anxiety of employees. Proceedings of the Latvian Academy of Sciences, 64(12), 85-91.

Zastrow, C. H. (2009). Social work with group: A comprehensive workbook (seventh edition). USA: Brook/Cole Cangage Learning. 